\title{
Teks Anekdot dalam Web Guru Pendidikan (Pola, Struktur, Pesan Moral, dan Relevansinya bagi Pembelajaran Bahasa Indonesia SMA Kelas X)
}

\author{
Anecdotal Texts in the Teacher Education Web \\ (Patterns, Structures, Moral Messages, and Their Relevance for Indonesian Language \\ Learning in Class X of High School) \\ ${ }^{1)}$ Mutiara Indah Fitria, ${ }^{2)}$ Kuntoro \\ ${ }^{1,2)}$ Universitas Muhammadiyah Purwokerto \\ *email: mutiaraindahfitria5@gmail.com
}

\begin{abstract}
Histori Artikel:
Diajukan:

05/09/2021

Diterima:

$09 / 10 / 2021$

Diterbitkan:

$08 / 12 / 2021$

ABSTRAK

Penelitian ini bertujuan mendeskripsikan pola, struktur, pesan moral, dan relevansi penelitian dengan pembelajaran bahasa Indonesia SMA Kelas X. Jenis penelitian ini adalah deskriptif kualitatif. Pendekatan yang digunakan adalah pendekatan pragmatik. Data pada penelitian ini adalah teks yang mengandung unsur Pola, Struktur, Pesan Moral di dalam teks anekdot Web Guru Pendidikan. Sumber data pada penelitian ini adalah teks anekdot Web Guru Pendidikan. Teknik pengumpulan data penelitian ini menggunakan teknik baca dan teknik catat. Teknik analisis datanya meliputi reduksi data, menyajikan data, dan kesimpulan. Validitas data menggunakan triangulasi teori. Hasil penelitian ini yaitu (1) 31 data dari teks anekdot menggunakan pola narasi, (2) 37 data teks anekdot menggunakan pola dialog, (3) 1 data menggunakan pola anekdot dan pola narasi. Struktur teks anekdot (1) 1 data terdapat struktur abstrak, orientasi, krisis, reaksi, dan koda, (2) 55 data terdapat struktur abstrak, orientasi, krisis, dan reaksi, (3) 1 data terdapat struktur abstrak, orientasi, krisis, dan koda, (4) 4 data merupakan struktur yang terdiri dari abstrak, krisis, reaksi, dan (5) 8 data terdapat struktur abstrak, orientasi, dan krisis. Menemukan 9 pesan moral (1) menghargai orang lain, (2) disiplin, (3) jujur, (4) kerja keras, (5) adil, (6) bertanggung jawab, (7) religius, (8) demokratis, (9) toleransi. Berdasarkan relevansi penelitian terhadap pembelajaran, penelitian ini dapat digunakan sebagai bahan ajar siswa dan sebagai media pendidikan karakter.
\end{abstract}

Kata kunci: Pola Anekdot, Struktur Teks Anekdot, Pesan Moral, Bahan Ajar

\begin{abstract}
This study aims to describe the pattern, structure, moral message, and the relevance of research with learning Indonesian in SMA Class X. This type of research is descriptive qualitative. The approach used is a pragmatic approach. The data in this study is a text that contains elements of Pattern, Structure, Moral Message in the anecdotal text of the Education Teacher Web. The source of the data in this research is the anecdotal text of the Education Teacher Web. The data collection technique of this research used reading and note-taking techniques. The data analysis technique includes data reduction, data presentation, and conclusions. The validity of the data using theoretical triangulation. The results of this study are (1) 31 data from anecdotal texts using narrative patterns, (2) 37 anecdotal text data using dialogue patterns, (3) 1 data using anecdotal patterns and narrative patterns. The structure of anecdotal text (1) 1 data contains abstract structure, orientation, crisis, reaction, and code, (2) 55 data contains abstract structure, orientation, crisis, and reaction, (3) 1 data contains abstract structure, orientation, crisis, and coda, (4) 4 data is a structure consisting of abstract, crisis, reaction, and (5) 8 data contains abstract structure, orientation, and crisis. Finding 9 moral messages (1) respecting others, (2) discipline, (3) honest, (4) hard work, (5) fair, (6) responsible, (7) religious, (8) democratic, (9)
\end{abstract}


tolerance. Based on the relevance of research to learning, this research can be used as student teaching materials and as a medium for character education.

Keywords: Anecdotal Patterns, Anecdotal Text Structure, Moral Messages, Teaching Materials

\section{PENDAHULUAN}

Teks anekdot adalah teks atau wacana yang bermuatan humor untuk menyindir, bersunda gurau, atau mengkritik secara tidak langsung segala macam kepincangan atau ketidakberesan yang tengah terjadi di kalangan masyarakat penciptanya (Wijana, 1995:24). Selain itu Keraf (2007:142) mengatakan bahwa pengertian teks anekdot adalah semacam cerita pendek yang bertujuan menyampaikan karakteristik yang menarik atau aneh mengenai seseorang atau suatu hal lain. Jadi anekdot bisa diartikan sebagai cerpen yang berkarakter dan di dalamnya mengandung kritikan yang membangun. Bisa juga diartikan sebagai cerita lucu yang bertujuan untuk mengkritik seseorang atau suatu hal. Berdasarkan pendapat ahli di atas, dapat disimpulkan bahwa teks anekdot merupakan sebuah cerita pendek atau singkat yang berisi humor untuk mengkritik atau menyindir seseorang atau suatu hal yang dianggap penting di masyarakat. Selain itu, teks anekdot sendiri merupakan sebuah cerita singkat dan lucu atau menarik, yang mungkin menggambarkan kejadian atau orang sebenarnya. Anekdot bisa saja sesingkat pengaturan dan provokasi dari sebuah kelakar. pendapat para ahli di atas diperkuat oleh pendapat Chaer (2011:158) bahwa anekdot merupakan cerita singkat yang lucu mengenai seorang tokoh terkenal, yang ada atau pernah ada. Jadi, tokoh dalam anekdot bukan tokoh fiktif, melainkan tokoh nyata yang ada dalam sejarah. Hal ini menunjukkan bahwa humor mungkin sudah ada bahkan sebelum manusia mengenal bahasa. Hampir setiap saat seseorang mengusahakan dan merangsang agar bisa tertawa dengan berbagai macam kejadian yang pernah dialaminya. Dalam bukunya yang berjudul "Teks dalam Pembelajaran Bahasa Indonesia Kurikulum 2013", Mahsun (2014) menyebutkan bahwa teks anekdot sebagai salah satu jenis teks yang termasuk dalam genre cerita, teks anekdot memiliki tujuan sosial yang sama dengan teks cerita ulang.

Pembelajaran bahasa Indonesia pada kurikulum 2013 mempelajari teks yang berbeda- beda pada setiap KD yang telah ditetapkan di kurikulum 2013. Teks-teks tersebut terbagi pada kompetensi-kompetensi yang terdapat di dalam silabus. Salah satu kompetensi dasar (KD) yang harus dicapai dalam pelajaran bahasa Indonesia menurut kurikulum 2013 untuk siswa kelas X SMA adalah mengenai teks anekdot. Munculnya teks anekdot sebagai teks yang diajarkan dalam mata pelajaran bahasa Indonesia baru disampaikan secara tersurat dalam kurikulum 2013. Sesuai dengan prinsip pembelajaran bahasa Indonesia dalam kurikulum tersebut yakni berbasis teks. Teks anekdot menjadi salah satu teks yang wajib dipelajari siswa. Hanya saja teks anekdot baru dikenalkan mulai jenjang SMA/ MA/ SMK, karena hal tersebut siswa yang baru saja mempelajari teks anekdot tentu saja akan mengalami kesulitan dalam memahami secara mendalam mengenai teks anekdot. Pembelajaran teks anekdot dapat dikaitkan dengan pembelajaran bahasa Indonesia di SMA kelas X. Pembelajaran teks anekdot di SMA kelas $\mathrm{X}$ mempelajari terkait mengkritisi teks anekdot dari aspek makna tersirat, menemukan makna tersirat dilakukan dengan memahami isi anekdot, menghubungkan makna dengan fakta, dan nilai-nilai kehidupan. Tujuan dilakukannya penelitian ini adalah agar siswa dapat memperdalam pengetahuannya mengenai teks anekdot dan dapat memahami pesan moral yang terdapat di dalamnya sehingga akan memberikan pendidikan karakter yang baik untuk siswa. Tentu saja memperdalam pengetahuan di dalam teks anekdot berkaitan dengan tujuan pembelajarannya dan sejalan dengan penelitian yang membahas mengenai pola teks anekdot, struktur, pesan moral, dan kaitannya dengan pembelajaran di sekolah. Pendidikan karakter menjadi penting dalam kebijakan nasional di bidang karakter pendidikan. Menurut Rusdiana (2014: 105) Dalam Undang-Undang Republik Indonesia Nomor 20 tahun 2004 tentang Sistem Pendidikan Nasional (UU Sisdiknas) dirumuskan fungsi dan tujuan pendidikan nasional yang harus digunakan dalam mengembangkan upaya pendidikan di Indonesia. Pasak 33 UU Sisdiknas menyatakan: 
"Pendidikan nasional berfungsi mengembangkan dan membentuk watak serta peradaban bangsa yang bermartabat dalam rangka mencerdaskan anak bangsa, betujuan untuk berkembangnya potensi peserta didik agar menjadi manusia yang beriman dan bertakwa kepada Tuhan Yang Maha Esa, berakhlak mulia, sehat, berilmu, cakap, kreatif,, mandiri, dan menjadi warga negara yang demokratis seta bertanggung jawab." Oleh karena itu, Ratna (2014: 199) mengungkapkan pendidikan karakter jelas bertujuan agar pembunuhan, kebohongan, dan segala bentuk kejahatan bukan untuk ditiru, melainkan untuk ditolak, dihindarkan sejauh-jauhnya dari kehidupan manusia.

Menurut Arief (2011:8) web adalah salah satu aplikasi yang berisikan dokumendokumen multimedia (teks, gambar, animasi, video) di dalamnya yang menggunakan protokol HTTP (Hypertext Transfer Protocol) dan untuk mengaksesnya menggunakan perangkat lunak yang disebut browser. Kemudian Abdullah (2015:1) mengatakan bahwa website dapat diartikan sekumpulan halaman yang terdiri dari beberapa laman yang berisi informasi dalam bentuk data digital baik berupa text, gambar, video, audio, dan animasi lainnya yang disediakan melalui jalur koneksi internet. Sementara itu, Bekti (2015:35) mengatakan bahwa website merupakan kumpulan halamanhalaman yang digunakan untuk menampilkan informasi teks, gambar diam atau gerak, animasi, suara, dan atau gabungan dari semuanya, baik yang bersifat statis maupun dinamis yang membentuk satu rangkaian bangunan yang saling terkait, yang masingmasing dihubungkan dengan jaringan-jaringan halaman. Berdasarkan pendapat ahli di atas, dapat disimpulkan bahwa website adalah kumpulan halaman-halaman yang berkaitan dengan dokumen yang berisi teks, gambar, multimedia yang berisi tentang informasi yang disediakan melalui jalur koneksi internet.

Web Guru Pendidikan sendiri merupakan sebuah website dengan nama Web Guru Pendidikan yang merupakan suatu dokumen berupa sekumpulan halaman yang berisi berbagai informasi berbentuk digital. Informasi itu bisa berupa teks, gambar, animasi, video atau gabungan dari semuanya yang disediakan melalui internet dan dapat diakses oleh banyak orang di seluruh dunia selama memiliki koneksi internet. Di dalam Web Guru Pendidikan, terdapat informasi mengenai dokumen-dokumen yang berisi tentang segala sesuatu terkait dengan materi pembelajaran di sekolah baik jenjang SMP, SMA, SMK, S1, S2, maupun jenjang umum. Sebagai contoh, untuk mata pelajaran bahasa Indonesia SMA Kelas X berisi mengenai materi-materi teks anekdot dan teks lainnya juga. Untuk jenjang SMP, SMA, terdapat materi untuk mata pelajaran agama, bahasa Indonesia, Kewarganegaraan, Pancasila, IPA, IPS, kemudian untuk S1 dan S2 juga terdapat materi terkait program studi yang ada di jenjang pendidikan tersebut. Web Guru Pendidikan ini merupakan website interaktif yang merupakan suatu website yang diperuntukkan untuk berinteraksi dengan orang lain secara online. Pengguna website jenis ini biasanya komunitas atau pengguna internet aktif. Pengguna di website ini dapat berinteraksi dan beradu argumen tentang apa yang sedang mereka pikirkan. Sehingga Web Guru Pendidikan ini akan terus diperbarui sesuai dengan perkembangan materi pada pembelajaran di setiap jenjang pendidikan. Web Guru Pendidikan dapat diakses dengan menuliskan www.gurupendidikan.co.id di google atau di internet lainnya.

Setelah peneliti melakukan pencarian, terdapat banyak contoh teks anekdot dalam berbagai tema di dalam Web Guru Pendidikan. Teks-teks di dalam Web tersebut hanya dilampirkan sebagai contoh teks anekdot, tetapi penulis berpikir untuk menggunakan teks-teks anekdot di dalam Web tersebut sebagai objek untuk penelitian ini. Hal ini menarik untuk diteliti agar siswa dapat memperdalam pengetahuannya mengenai teks anekdot yang baru dipelajarinya dijenjang SMA dan dapat memahami pesan moral yang ada di dalam teks anekdot sehingga dapat diterapkan di kehidupan sehari-hari. Untuk itu, peneliti akan melakukan penelitian dengan judul Teks Anekdot dalam Web Guru Pendidikan (Pola, Struktur, Pesan Moral, dan Relevansinya bagi Pembelajaran Bahasa Indonesia SMA Kelas X).

\section{METODE}

Dalam penelitian ini, penulis menggunakan pendekatan kualitatif. Penelitian kualitatif merupakan penelitian yang bersifat deskriptif dan cenderung menggunakan analisis. Proses dan makna lebih ditonjolkan dalam 
penelitian kualitatif dan landasan teori dimanfaatkan sebagai pemandu penelitian. Kemudian untuk metode penelitian, metode penelitian ini juga menggunakan metode deskriptif. Karena hal itu, penelitian ini menggunakan metode penelitian deskriptif kualitatif. Objek penelitian ini adalah Teks Anekdot dalam Web Guru Pendidikan (Pola, Struktur, Pesan Moral, dan Relevansinya bagi Pembelajaran Bahasa Indonesia SMA Kelas X). Data yang ada di dalam penelitian ini berupa kata, kalimat, dialog, dan ungkapan pada paragraf di dalam kumpulan teks anekdot dalam Web Guru Pendidikan. Kata, kalimat, dialog, dan ungkapan pada paragraf ini menjadi data utama dalam kajian. Sedangkan sumber data yang digunakan penelitian ini adalah kumpulan teks anekdot dalam Web Guru Pendidikan. Teknik pengumpulan data pada penelitian ini adalah dengan menggunakan teknik baca dan teknik catat. Teknik baca dilakukan dengan membaca kumpulan teks anekdot dalam web guru pendidikan januari 2021. Setelah membacanya, kemudian dilakukan teknik catat. Teknik catat dilakukan untuk mencatat apa saja data-data yang sesuai dengan penelitian yang akan dilakukan. Teknik catat ini diambil dari data-data mengenai teks anekdot dalam Web Guru Pendidikan. Teknik analisis data adalah teknik untuk menganalisis data yang akan diteliti. Ada 3 tahapan analisis data kualitatif dalam tesis ini, yaitu reduksi data, menyajikan data, dan kesimpulan/verifikasi.

\section{HASIL DAN PEMBAHASAN}

\section{Pola-Pola Anekdot Pada Teks Anekdot Web Guru Pendidikan \\ Pola Narasi}

\section{a. Pola Pengembangan Kronologis Waktu}

\section{Judul: Saling}

Ketika sedang musim pemilihan kepala desa, Kasiman didatangi tim sukses dari balon (bakal calon) kades nomor 1. Ia menerima amplop berisi uang dari mereka.

"Jangan lupa pilih nomor 1, ya."

"Siaap," jawab Kasiman.

Tak lama setelahnya, datang tim sukses dari balon kades nomor 2. Ia juga menerima amplop berisi uang dari mereka.

"Ingat lho, pilih nomor 2, OK?"

"Beress," sahut Kasiman.
Istrinya bertanya, "Mas, kok dua-duanya di-iyain, nanti gimana? Mas nggak mikirin kalau ada yang kalah bakal kecewa?"

Kasiman menjawab santai, "Halah, Bu. Habis kepilih juga mereka belum tentu bakal ada yang mikirin kita. Kalau mereka memanfaatkan kita, ya kita juga manfaatkan mereka balik, lah.Hehe.."

Sang istri mengangguk-angguk. "Benar juga, Mas." (PA/PN/PPW/03)

Pola yang digunakan pada teks anekdot tersebut adalah pola narasi. dalam pola ini, kejadian-kejadian yang diceritakan disampaikan dengan urutan waktu, misalnya dari pagi hingga pagi lagi, dari zaman dulu sampai zaman sekarang, dari permulaan hingga selesai, dan sebagainya. karena teks di atas pola penyajian laporan yang bersifat narasi, lebih menekankan pada uraian secara kronologis, yakni berdasarkan pada rangkaian waktu. Isi laporan ini bersifat penceritaan peristiwa mengenai objek yang dilaporkan. Seperti teks di atas menceritakan dari awal hingga selesai.

\section{b. Pola Pengembangan Spasial Ruang}

Judul: Konferensi Binatang

Haji Agus Salim merupakan seorang tokoh nasional yang memiliki jenggot panjang. Sebagai seorang tokoh, ada saja yang merasa tidak suka dengan H. Agus Salim.

Satu ketika, Haji Agus Salim sedang berbicara dalam sebuah konferensi. Ketika sedang berpidato, tiba-tiba ada yang mengejeknya dengan mengeluarkan suara, "Embeek.. Embeek..."

Ketika makin lama suara itu makin keras dan mulai mengganggu, H. Agus Salim akhirnya angkat suara. "Panitia, setahu saya, saya diundang dalam konferensi untuk manusia. Kenapa bisa ada binatang yang hadir di pojok sana?"

Seketika para hadirin tertawa ringan, sedangkan yang tadi bersuara langsung diam, malu. (PA/PN/PPR/05)

Pola pengembangan spasial (ruang) yang menceritakan kejadian secara acak namun dapat menggabungkan cerita dengan indah. Pada pola pengembangan spasial cerita ini menggunakan pengembangan ruang berdasarkan tempat. Dimulai secara acak saat menjelaskan 1. Haji Agus Salim merupakan seorang tokoh nasional yang memiliki jenggot panjang. Sebagai seorang 
tokoh, ada saja yang merasa tidak suka dengan H. Agus Salim. 2. Satu ketika, Haji Agus Salim sedang berbicara dalam sebuah konferensi. Ketika sedang berpidato, tiba-tiba ada yang mengejeknya dengan mengeluarkan suara, "Embeek.. Embeek..." 3. Ketika makin lama suara itu makin keras dan mulai mengganggu, H. Agus Salim akhirnya angkat suara. "Panitia, setahu saya, saya diundang dalam konferensi untuk manusia. Kenapa bisa ada binatang yang hadir di pojok sana?" 4. Seketika para hadirin tertawa ringan, sedangkan yang tadi bersuara langsung diam, malu.

\section{Pola Alih Tutur Bardasarkan Pasangan Ujaran Terdekat}

Pasangan ujaran terdekat dapat dirangkaikan menjadi akronim PUT. Pola alih tutur berdasarkan PUT dapat dideskripsikan dengan beberapa kemungkinan, seperti:

\section{a. Tanya diikuti jawab}

Sebuah ujaran yang berupa tanya dalam teks anekdot pola dialog, terdapat beberapa perbedaan yang dimunculkan oleh mitra tuturnya.

Judul: Moody

Cewek :Priit

Pemain :Lho, kok sudah selesai, sih? Kan belum 90 menit?(1)

Cewek :Biarin. Udah nggak mood buat lanjutin. (2)

Pemain: (Guling-guling di rumput) (PA/PD/TDJ/01)

Pada percakapan 1 dan 2 terdapat pasangan ujaran terdekat tanya diikuti jawab. Pola teks di atas adalah tanya diikuti jawab. Hanya terdapat 1 pola pasang ujaran terdekat dalam teks anekdot di atas. Pada percakapan 1 pemain sebagai penutur sebelumnya mengungkapkan ujaran berupa tanya yang ditujukan kepada mitra tuturnya yaitu cewek. Pada percakapan 1 pemain bertanya kepada cewek, kemudian pada percakapan 2 cewek langsung merespon dengan menjawab pertanyaan yang ditujukan padanya. Selain itu pola dialog terlihat dari ciri bahwa terdapat nama di depan percakapan, lalu percakapan menggunakan kalimat langsung.

b. Menuduh diikuti mengakui, mengingkari, membenarkan, memaafkan diri, dan menentang
Sebuah ujaran yang berupa menuduh dalam teks anekdot, memunculkan beberapa tanggapan yang berbeda.

Judul: Banyak Alasan

Cewek :Priit (1)

Pemain :Kenapa, Sit? Kita nggak ngapai-ngapain. (2)

Cewek :Kamu tadi mau nyeleding tackle, kan?(3)

Pemain :Lah, kan belum diapa-apain, Sit?(4)

Cewek :Belum itu berarti mau. Udah, deh, nggak usah banyak alasan. Pokoknya kamu kartu kuning. (5)

Pemain :(makan rumput lapangan) (PA/PD/MMMMMM/01)

Pada percakapan 1 dan 2, 3 dan 4 terdapat pasangan ujaran terdekat menuduh diikuti mengingkari. Cewek sebagai penutur sebelumnya mengungkapkan ujaran berupa menuduh yang ditujukan kepada mitra tuturnya yaitu Pemain. Percakapan 1 Cewek terlebih dahulu mengungkapkan ujaran berupa menuduh kepada Pemain dengan membunyikan peluit untuk menghentikan permainan. Kemudian pada percakapan 2, pemain langsung merespon dengan menjawab ujaran tuduhan yang ditujukan padanya dengan cara mengingkari tuduhan tersebut. Pada percakapan 3, Cewek melanjutkan lagi ujaran berupa menuduh tersebut kepada mitra tutur yang sama yaitu Pemain. Kemudian pada percakapan 4, Pemain langsung merespon dengan menjawab ujaran tuduhan yang ditujukan padanya dengan cara menentang. Pada teks anekdot di atas, pola dialog yang terdapat di atas dapat dilihat bahwa pada dialog antar tokoh menggunakan kalimat langsung dan bukan kalimat pasif seperti pada pola narasi. Kemudian pola dialog menggunakan nama di depan sebelum titik dua dan memulai percakapan.

\section{c. Menawari diikuti menerima dan me- nolak}

Menawari merupakan sebuah ungkapan yang mengajak orang lain agar tertarik dengan apa yang diberikan atau diperlihatkan. Sebuah ujaran yang berupa menawari dalam teks anekdot, terdapat beberapa tanggapan yang dimunculkan.

Judul: Soal yang Mudah 
Ketika penilaian tahap akhir di SD Sukamandi, Bu Wati sedang mengawasi murid kelas 4.

Ujian sudah dimulai sejak setengah jam yang lalu. Hingga saat ini, murid-murid terlihat tegang. Bu Wati ingin membuat mereka lebih rileks.

Bu Wati Gimana, anak-anak, soalnya mudah semua, kan?(1)

Murid-murid :Mudah, Bu guru. (2)

Bu Wati :Alhamdulillah, kalau memang gampang semua.

Ngadimin :Soalnya sih gampang semua, Bu. Tapi jawabannya yang susah.

Bu Wati :Kok, bisa? Memangnya kamu tidak belajar, Ngadimin?

Paimin :Dia mah nggak pernah belajar, Bu. Tiap malam ngajakin mabar Mobile Legend.

Bu Wati

:Hemm.

pantess..

\section{(PA/PD/MMM/01)}

Percakapan 1 dan 2 terdapat ujaran terdekat menawari diikuti menerima. Pada percakapan 1 $\mathrm{Bu}$ Wati sebagai penutur sebelumnya mengungkapkan ujaran berupa menawari yang ditujukan kepada mitra tuturnya yaitu muridmuridnya. Pada percakapan $1 \mathrm{Bu}$ Wati menawari pertanyaan bahwa soal itu mudah kepada murid-muridnya, kemudian pada percakapan 2 murid-muridnya langsung merespon dengan cara menerima tawaran dari $\mathrm{Bu}$ Wati bahwa soalnya memang mudah. Pada teks anekdot di atas, pola dialog yang terdapat di atas dapat dilihat bahwa pada dialog antar tokoh menggunakan kalimat langsung dan bukan kalimat pasif seperti pada pola narasi. Kemudian pola dialog menggunakan nama di depan sebelum titik dua dan memulai percakapan.

\section{d. Memohon diikuti mengabulkan, menangguhkan, menolak, dan menantang.}

Memohon dalam Kamus Besar Bahasa Indonesia merupakan sebuah ungkapan yang meminta dengan hormat seseorang untuk membantu atau melakukan yang kita katakan. Sebuah ujaran yang berupa memohon dalam teks anekdot Web Guru Pendidikan, terdapat beberapa tanggapan yang dimunculkan.

Judul: Bencong Badminton

Mince merupakan waria terkenal di kampung Suka Gosip. Suatu hari kampung mengadakan lomba badminton. Mince yang sejak kecil suka Badminton ingin ikut bermain. Ia pun menghubungi bagian pendaftaran.

Mince :Om, mince mau daftar badminton duong, ikut tunggal putri (1)

Panitia : Kagak bisa mamase, eh, mbak'e. Kuota udah habis.(2)

Mince :Yaah.. yaudah, mince ditaro di tunggal laki-laki nggak apa deh, ikhlas. (3)

Panitia :Waah, penuh juga mas. Nggak bisa jadinya. (4)

Mince :Apaan sih, penuh mulu, cebeel deh. Ya udah di ganda. Mau ganda putri, ganda putra, campuran, apa aja, yang penting Mince ikut. Siapa tahu Mince sekalian dapat pasangan. Hihi.. (5)

Panitia :Udah nggak ada, Mincee. Mau tunggal, ganda, triple, semua udah habiis.. (6)

Mince :Iiih.. siapa sih yang ngabisin jatah semua. Yaudah Mince bikin kategori baru, TUNGGAL CAMPURAN. Bisa $y a$, mas ganteng?

Panitia pun langsung gantung diri di pohon toge. (PA/PD/MMMMM/01)

Percakapan 1 dan 2, 3 dan 4, 5 dan 6 terdapat pasangan ujaran terdekat memohon diikuti menolak. Mince sebagai penutur sebelumnya mengungkapkan ujaran berupa memohon yang ditujukan kepada beberapa mitra tuturnya yaitu Panitia dalam waktu dan tempat yang sama atau memohon berurutan. Pada percakapan 1 Mince terlebih dahulu mengungkapkan ujaran berupa memohon kepada Panitia yang sedang ada dibagian pendaftaran lomba. Kemudian pada percakapan 2 Panitia langsung merespon dengan menjawab ujaran memohon yang ditujukan padanya dengan cara menolak permohonan Mince. Setelah itu, pada percakapan 3 Mince mengungkapkan ujaran berupa memohon kepada mitra tutur yang sama yaitu Panitia. Pada percakapan 4, Panitia langsung merespon dengan menjawab ujaran memohon tersebut dengan cara menolak permohonan Mince lagi. Kemudian, Mince kembali mengungkapkan lagi ujaran memohon yang sama pada Panitia pada percakapan 5. Pada percakapan 6 Panitia langsung merespon dengan menjawab ujaran memohon yang ditujukan padanya dengan cara menolak untuk ketiga kalinya permohonan 
Mince. Pada teks anekdot di atas, pola dialog yang terdapat di atas dapat dilihat bahwa pada dialog antar tokoh menggunakan kalimat langsung dan bukan kalimat pasif seperti pada pola narasi. Kemudian pola dialog menggunakan nama di depan sebelum titik dua dan memulai percakapan.

\section{A. Struktur Teks Anekdot Pada Teks Anekdot Web Guru Pendidikan}

Judul: Pocong

Kantor BPJS kota Sudimara dalam keadaan kacau balau. Semua pegawai meringkuk di sudut kantor, sementara para pocong menyerbu ke dalam. Kepala cabang terlihat gemuk dan berkecukupan itu berusaha meredam situasi. Ia berusaha negosiasi dengan para pocong.

"Maaf, Tuan Pocong, kalau boleh tahu, ada gerangan apa ramai-ramai ke sini. Padahal kami tidak mengadakan acara tahlilan atau kenduri. Tahlilan atau kenduri kan bukan tanggungan BPJS Kesehatan."

Pocong yang paling tua menjawab, "Oh, kami di sini mau mengundurkan diri dari BPJS Kesehatan. Karena kalau sudah meninggal kan, klaimnya tidak bisa diwariskan, sedangkan tagihannya tetap harus dibayar ahli waris. Makanya kami ke sini untuk menutup akun BPJS. ”

"Ooh, kalau cuma itu, ahli warisnya saja bisa kok, asal bawa surat keterangan kematian. Ndak perlu sampeyan-sampeyan yang ke sini sendiri," pak Kepala menjelaskan.

"Nganu, pak. Kemarin pas kita ngadu lewat laman twitter, katanya pengurusan BPJS yang meninggal, yang bersangkutan agar datang ke kantor BPJS. "

"Hee.. ngene, pak. Si mas ngademin twitter memang suka becanda, suka bermain-main kata. Begitu, pak," ujar pak Kepala sambil pasang senyum kuda.

"Oalah, ngono toh, pak. Yo wis, tah. Kita balik kalau begitu," kata tetua pocong sambil berbalik. "Bapak ndak mau ikut ke tempat kami?"

"Eeh.. ndak usah, Pak. Saya masih mau jadi kepala BPJS. Gajinya lumayan,” tolak pak Kepala, buru-buru.
"Hee.. santai aja, Pak. Kami juga suka becanda. Suka main-main kata."

Dan tetua pocong pun pulang beserta rombongan, meninggalkan kepala BPJS yang meneteskan keringat dingin. 


\begin{tabular}{|l|l|}
\hline Abstrak & $\begin{array}{l}\text { Kantor BPJS kota Sudimara dalam keadaan kacau balau. Semua pegawai meringkuk } \\
\text { di sudut kantor, sementara para pocong menyerbu ke dalam. Kepala cabang terlihat } \\
\text { gemuk dan berkecukupan itu berusaha meredam situasi. Ia berusaha negosiasi dengan } \\
\text { para pocong. }\end{array}$ \\
\hline Orientasi & $\begin{array}{l}\text { "Maaf, Tuan Pocong, kalau boleh tahu, ada gerangan apa ramai-ramai ke sini. } \\
\text { Padahal kami tidak mengadakan acara tahlilan atau kenduri. Tahlilan atau kenduri } \\
\text { kan bukan tanggungan BPJS Kesehatan." } \\
\text { Pocong yang paling tua menjawab, "Oh, kami di sini mau mengundurkan diri dari } \\
\text { BPJS Kesehatan. Karena kalau sudah meninggal kan, klaimnya tidak bisa diwariskan, } \\
\text { sedangkan tagihannya tetap harus dibayar ahli waris. Makanya kami ke sini untuk } \\
\text { menutup akun BPJS." }\end{array}$ \\
\hline Krisis & $\begin{array}{l}\text { "Ooh, kalau cuma itu, ahli warisnya saja bisa kok, asal bawa surat keterangan } \\
\text { kematian. Ndak perlu sampeyan-sampeyan yang ke sini sendiri," pak Kepala } \\
\text { menjelaskan. } \\
\text { "Nganu, pak. Kemarin pas kita ngadu lewat laman twitter, katanya pengurusan BPJS } \\
\text { yang meninggal, yang bersangkutan agar datang ke kantor BPJS." } \\
\text { "Hee.. ngene, pak. Si mas ngademin twitter memang suka becanda, suka bermain- } \\
\text { main kata. Begitu, pak," ujar pak Kepala sambil pasang senyum kuda. } \\
\text { "Oalah, ngono toh, pak. Yo wis, tah. Kita balik kalau begitu," kata tetua pocong } \\
\text { sambil berbalik. "Bapak ndak mau ikut ke tempat kami?" } \\
\text { "Eeh.. ndak usah, Pak. Saya masih mau jadi kepala BPJS. Gajinya lumayan," tolak } \\
\text { pak Kepala, buru-buru. }\end{array}$ \\
\hline Reaksi & $\begin{array}{l}\text { "Hee.. santai aja, Pak. Kami juga suka becanda. Suka main-main kata." } \\
\text { meneteskan keringat dingin. (SA/SL/AOKRK/01) }\end{array}$ \\
\hline
\end{tabular}


Struktur teks anekdot yang lengkap menurut Kemendikbud ada lima yang juga dimiliki oleh teks anekdot di atas, yaitu abstrak yang merupakan kepala cabang yang mencoba berdamai dengan para pocong, kemudian bagian orientasi yang menjadi penyebab timbulnya krisis yaitu saat pocong ingin menutup akun. Kemudian bagian krisis tentang pengurusan BPJS yang sudah meninggal tetapi datang ke kantor, akhirnya reaksinya adalah bahwa dia hanya main-main. Kemudian bagian koda, atau penutup yaitu pocong pulang beserta rombongan dan kepala BPJS berkeringat dingin. Teks di atas memiliki struktur lengkap karena memiliki lima unsur yang disampaikan para ahli di dalam teorinya.

Pak Guru sedang menyidang 3 orang anak yang kemarin tidak masuk sekolah tanpa keterangan. Tiga orang tersebut adalah Denda, Dendi, dan Dandi.

Pak. Denda, kenapa kamu kemarin tidak

Guru' masuk sekolah?

Maaf, Pak. Ada orang tidak

Denda : bertanggung jawab yang menabrak saya.

Pak . Dendi, kenapa kamu juga tidak masuk Guru 'sekolah kemarin?

Maaf, pak. Kemarin saya kecelakaan.

Dendi : Saya nabrak anak gila yang main bola di jalanan.

Pak Dandi, kamu juga apa kecelakaan

Guru 'kemarin?

Tidak, Pak. Saya telah karena jalannya

Dandi : macet gara-gara anak bodoh yang saling tabrakan waktu main bola di jalan.

Pak. Ya, kalau macet seharusnya kamu bisa Guru ' kan cari jalan lain?

Dandi : Nanti kalau saya cari jalan lain, yang jadi wasitnya siapa, dong, Pak? 


\begin{tabular}{|c|c|}
\hline Abstrak & $\begin{array}{l}\text { Pak Guru sedang menyidang } 3 \text { orang anak yang kemarin tidak masuk sekolah tanpa } \\
\text { keterangan. Tiga orang tersebut adalah Denda, Dendi, dan Dandi. }\end{array}$ \\
\hline Orientasi & 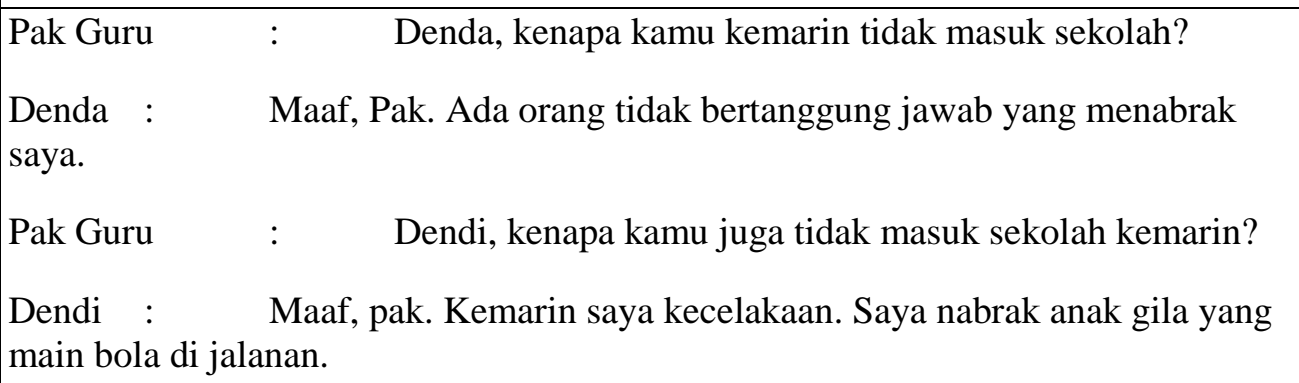 \\
\hline Krisis & 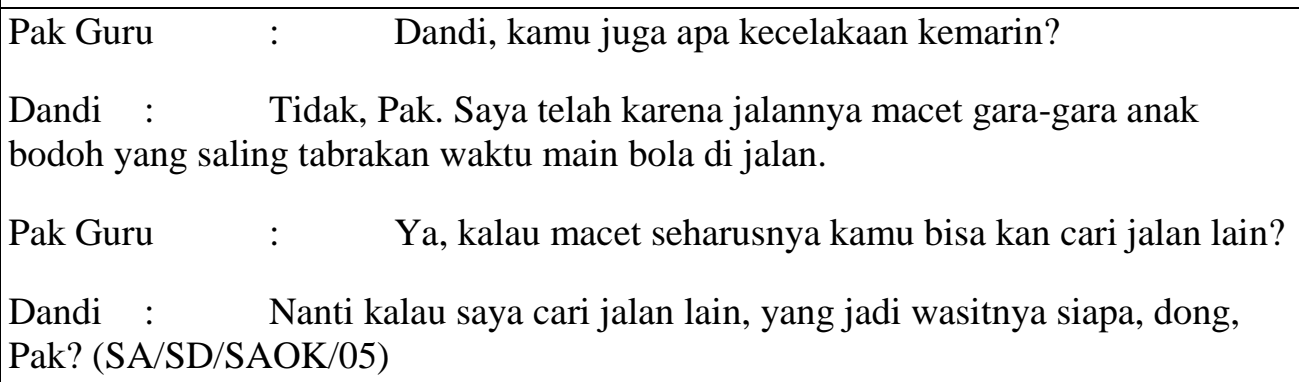 \\
\hline
\end{tabular}


Pada teks anekdot di atas terdapat tiga struktur teks anekdot yaitu abstrak, orientasi, dan krisis. Abstrak, yaitu bagian awal teks anekdot yang berfungsi memberikan gambaran tentang isi teks. Biasanya bagian ini menunjukkan hal unik yang akan ada di dalam teks. Abstrak dapat disebut sebagai tahap pembukaan. Abstrak diawali dengan Pak Guru sedang menyidang 3 orang anak yang kemarin tidak masuk sekolah tanpa keterangan. Tiga orang tersebut adalah Denda, Dendi, dan Dandi. 2. Orientasi, yaitu bagian tes yang menunjukkan awal kejadian cerita atau latar belakang suatu peristiwa terjadi. Biasanya penulis bercerita dengan detil di bagian ini. Orientasi ini berfungsi untuk membangun teks. Orientasi dimulai dengan guru yang menanyakan mengapa muridnya kemarin tidak berangkat ke sekolah. 3. Krisis, yaitu bagian teks yang menunjukkan hal atau masalah yang unik dan tidak biasa yang terjadi pada penulis atau orang yang diceritakan. Krisis dimaknai sebagai saat terjadinya ketidakpuasan atau kejanggalan. Krisisnya ketika gurunya bertanya lebih jelas dan muridnya mengatakan yang sebenarnya alasan dia tidak ke sekolah. Struktur teks ini tidak memiliki reaksi dan koda. Sehingga dapat dikatakan bahwa struktur teks di atas tidak lengkap, atau juga disebut hanya menggunakan struktur dasarnya saja.

\section{B. Pesan Moral Pada Teks Anekdot Web Guru Pendidikan Menghargai Orang Lain}

Judul: Moody

Cewek : Priit

Pemain : Lho, kok sudah selesai, sih? Kan belum 90 menit?

Cewek : Biarin. Udah nggak mood buat lanjutin.

Pemain : (Guling-guling di rumput)

Pesan moral yang terdapat pada teks anekdot di atas adalah bahwa jangan berperilaku seenaknya hanya karena suasana hati tidak baik. Jika seperti itu, maka kemungkinan akan menyakiti orang lain semakin besar karena hanya mementingkan diri sendiri tanpa memikirkan posisi orang lain. Jika begitu, sama saja dengan egois yang hanya memikirkan diri sendiri. Harus lebih menghargai orang lain. Pesan moral pada teks di atas merupakan penyampaian pesan secara tidak langsung di mana maksud dan isinya terkesan tidak jelas. Dapat dikatakan bahwa pesan moral di atas menggunakan penyampaian secara implisit.

\section{Demokratis}

Judul: Presiden Gila

Satu ketika, Gusdur ditanya dalam sebuah acara talkshow di televisi.

\begin{tabular}{|c|c|}
\hline Penanya & $\begin{array}{l}\text { Gus, katanya Gusdur ini } \\
\text { : dianggap sebagai presiden yang } \\
\text { paling kocak dan paling lucu } \\
\text { sih. }\end{array}$ \\
\hline Gusdur & $\begin{array}{l}\text { Wah, ya nggak tahu. Yang jelas } \\
\text { : semua presiden Indonesia } \\
\text { itu dari pertama sampai saya } \\
\text { memang gila. }\end{array}$ \\
\hline Penanya & : Maksudnya gimana, tho, Gus? \\
\hline Gusdur & $\begin{array}{l}\text { Presiden pertama kita itu gila } \\
\text { wanita. Yang kedua, gila harta. } \\
\text { Nah, yang ketiga itu gila } \\
\text { teknologi. }\end{array}$ \\
\hline Penanya & $\begin{array}{l}\text { Lha, kalo sampeyan, yang } \\
\text { keempat, gila apa, Gus? }\end{array}$ \\
\hline Gusdur & $\begin{array}{l}\text { Kalo saya, yang milihnya orang } \\
\text { gila. }\end{array}$ \\
\hline Penanya & $\begin{array}{l}\text { Hahaa.. Bisa aja, Gus } \\
\text { (PM/DK/01) }\end{array}$ \\
\hline
\end{tabular}

Pesan moral yang terdapat pada teks anekdot di atas adalah bahwa sebelum memilih pemimpin sebaiknya masyarakat memikirkan terlebih dahulu dengan matang. Jangan memilih dengan sembarangan dan asal-asalan. 
Mutiara Indah Fitria, Kuntoro

Teks Anekdot dalam Web Guru Pendidikan

(Pola, Struktur, Pesan Moral, dan Relevansinya bagi Pembelajaran Bahasa Indonesia SMA Kelas X)

Karena pilihan masyarakat akan menentukan masa depan bangsa. Kita harus berperilaku dengan mencerminkan sikap demokratis. Pesan moral pada teks di atas merupakan penyampaian pesan secara tidak langsung di mana maksud dan isinya terkesan tidak jelas. Dapat dikatakan bahwa pesan moral di atas menggunakan penyampaian secara implisit.

\section{Relevansi Penelitian dengan Pembelajaran Bahasa Indonesia SMA Kelas X \\ Sebagai Bahan Ajar}

Sebagai bahan memungkinkan siswa dapat mempelajari suatu kompetensi atau KD secara runtut dan sistematis sehingga secara akumulatif mampu menguasai semua kompetensi secara utuh dan terpadu. Bahan ajar disusun dengan tujuan; menyediakan bahan ajar yang sesuai dengan tuntutan kurikulum dengan mempertimbangkan kebutuhan siswa, yakni bahan ajar yang sesuai dengan karakteristik dan setting atau lingkungan sosial siswa. Kemudian bahan ajar juga bertujuan untuk membantu siswa dalam memperoleh alternative bahan ajar di samping buku-buku teks yang terkadang sulit diperoleh, dan memudahan guru dalam melaksanakan pembelajaran. Untuk membangun karakter siswa, dibutuhkan pendidikan karakter dan anekdot yang merupakan teks yang mengandung unsur humor dan mengandung makna dan pesan yang dalam dapat menanamkan nilai karakter dan keteladanan pendidikan di sekolah. Tidak hanya di sekolah, siswa juga dapat mengetahui pesan moral yang terkandung di dalam teks anekdot. Implementasinya yang dapat dilakukan misalnya memberikan pembelajaran teks anekdot dengan memberikan bahan ajar sebagai sarana belajar praktis agar siswa dapat memahami setiap materi yang dituntut oleh kurikulum. Kesesuaian penyediaan bahan ajar penelitian ini pada materi teks anekdot pada mata pelajaran bahasa Indonesia kelas $\mathrm{X}$ adalah sesuai dengan pola teks anekdot, struktur teks anekdot, dan pada penjelasan makna tersirat yang terkandung dalam teks meskipun di dalam penelitian ini menganalisis pesan moral, tetapi hal tersebut mengandung makna akan nilai-nilai moral dan pesan tersirat yang ada di dalam teks anekdot. Selain itu, untuk penyediaan bahan ajar ini akan membantu memperkaya bahan untuk diajarkan kepada siswa. Kemudian juga dapat digunakan sebagai referensi bagi guru ataupun siswa untuk pembelajaran bahasa Indonesia SMA kelas X.

\section{Terkait KI, KD, dan Indikator}

Relevansi teks anekdot dari web guru pendidikan dengan pembelajaran bahasa Indonesia SMA kelas X yaitu karena di dalam teks anekdot web guru pendidikan terdapat 69 teks anekdot dari berbagai tema, ada pendidikan, sosial, budaya, humor, agama, olahraga, sejarah, bahkan ekonomi dan sebagainya. hal ini dapat memperkaya pengetahuan siswa dan dapat membuat siswa semakin mendalami dan menguasai materi pembelajaran teks anekdot. Di dalam penelitian ini, penulis menganalisis teks anekdot berdasarkan pola anekdot, struktur teks anekdot dan pesan moral yang ada di dalamnya. Penelitian ini relevan dengan KI, $\mathrm{KD}$, dan Indikator. Meskipun tidak relevan dengan seluruh isi $\mathrm{KI}, \mathrm{KD}$, dan Indikator, tetapi ada beberapa yang relevan dan dapat digunakan untuk pembelajaran karena ada bagian sesuai dengan $\mathrm{KI}, \mathrm{KD}$, dan Indikator. Sehingga penelitian teks anekdot yang menganalisis pola, struktur, dan pesan moral relevan dengan pembelajaran bahasa Indonesia untuk siswa SMA kelas X.

\section{Sebagai Pendidikan Karakter}

Relevansi teks anekdot web guru pendidikan dengan analisis pola, struktur, dan pesan moral terhadap pembelajaran bahasa Indonesia yang dikhususkan untuk materi teks anekdot relevan untuk pembelajaran anekdot. Hal tersebut berkaitan dengan pembelajaran anekdot SMA kelas X pada KD 3.5 Mengevaluasi teks anekdot dari aspek makna tersirat. 3.6 Menganalisis struktur dan kebahasaan teks anekdot. Dan KD 4.5 Mengontruksi makna yang tersirat dalam sebuah teks anekdot. Nilainilai karakter dan pesan moral yang terkandung di dalam teks anekdot sebagai media pendidikan karakter dalam pembelajaran teks anekdot agar siswa dapat 
Mutiara Indah Fitria, Kuntoro

Teks Anekdot dalam Web Guru Pendidikan

(Pola, Struktur, Pesan Moral, dan Relevansinya bagi Pembelajaran Bahasa Indonesia SMA Kelas X)

memahami dan meneladani nilai-nilai pendidikan karakter sehingga dapat memiliki moral yang baik. Dengan ditemukannya 9 nilai-nilai pendidikan karakter yang terdapat pada pesan moral dalam teks anekdot Web Guru Pendidikan, dapat menjadi media untuk memberikan pengajaran pada peserta didik tentang nilai-nilai pendidikan karakter dan nilai moral di dalam teks anekdot untuk diamalkan dalam kehidupan sehari-hari baik di sekolah, rumah, maupun lingkungan masyarakat dan dapat digunakan pada sesama teman, orang tua, guru, dan tetangga. Dengan mengamalkan nilai-nilai pendidikan karakter dan mengetahui pesan moral dalam teks, akan memperbaik diri dan memiliki karakter yang semakin baik.

\section{KESIMPULAN}

Berdasarkan hasil dan pembahasan penelitian ini, dapat disimpulkan bahwa pada teks anekdot web guru pendidikan yang dianalisis berdasarkan pola anekdot, struktur teks anekdot, pesan moral, dan relevansinya bagi pembelajaran teks anekdot, dapat dikatakan bahwa pola anekdot pada teks anekdot web guru pendidikan memiliki dua pola, yaitu pola narasi dan pola dialog. Hasil penelitian ini menunjukkan, pola-pola anekdot yang meliputi pola narasi dan pola dialog. Pola narasi dibagi menjadi dua yaitu pola pengembangan kronologis waktu yang ditemukan pada 24 teks anekdot, dan pola pengembangan spasial ruang yang terdapat pada 8 teks anekdot. Selain itu, pada pola dialog terdapat pola alih tutur berdasarkan pasangan ujaran terdekat menemukan, tanya diikuti jawab pada 24 teks anekdot, menuduh diikuti mengakui, mengingkari, membenarkan, memaafkan diri dan menentang terdapat pada 7 teks anekdot, menawari diikuti menerima dan menolak pada 2 teks anekdot, memohon diikuti mengabulkan, menangguhkan, menolak, menantang pada 2 teks anekdot, dan pujian diikuti menerima, menyetujui, menolak, menggeser, mengembalikan pada 1 teks anekdot. Dan 1 teks anekdot yang tidak termasuk ke dalam manapun. Untuk struktur teks anekdot ditemukan 1 teks anekdot yang memiliki struktur lengkap abstrak, orientasi, krisis, reaksi, dan koda. Ditemukan 55 teks anekdot dengan struktur lengkap yaitu abstrak, orientasi, krisis, dan reaksi. Kemudian ditemukan 1 teks anekdot yang memiliki struktur lengkap abstrak, orientasi, krisis, dan koda. Lalu ditemukan 4 teks anekdot dengan struktur dasar atau struktur tidak lengkap yaitu abstrak, krisis, reaksi, dan 8 teks anekdot dengan struktur dasar atau tidak lengkap dengan struktur abstrak, orientasi, krisis.

Selain itu, terdapat 9 pesan moral yang terdapat pada 69 teks anekdot setelah dilakukan penelitian. Pesan moral menghargai orang lain pada 20 teks anekdot, disiplin pada 7 teks, jujur pada 16 teks anekdot, kerja keras pada 16 teks, adil pada 2 teks, bertanggung jawab pada 10 teks, religius pada 5 teks, demokratis pada 1 teks dan toleransi pada 2 teks. Kemudian berdasarkan relevansi penelitian terhadap pembelajaran, diketahui bahwa penelitian ini dapat digunakan sebagai bahan ajar siswa untuk mata pelajaran bahasa Indonesia khususnya materi teks anekdot. Selain sebagai bahan ajar, penelitian ini dapat digunakan untuk memperkaya materi untuk gruu mengajar siswa. Penelitian ini juga terkait dengan $\mathrm{KI}$, KD, dan Indikator sehingga relevan dengan pembelajaran, kemudian penelitian ini juga relevan digunakan sebagai pendidikan karakter bagi siswa untuk diajarkan di sekolah.

Berdasarkan hasil penelitian Teks Anekdot Web Guru Pendidikan (Pola, Struktur, Pesan Moral) dan Relevansinya bagi Pembelajaran Bahasa Indonesia SMA Kelas X, maka dapat dikemukakan saran sebagai berikut: 1) Bagi Pembaca, penelitian ini dapat digunakan sebagai bahan bacaan dan dapat dijadikan pelajaran mengenai teks anekdot dan menghubungkan dengan kehidupan sehari-hari sehingga dapat mengetahui tentang teks anekdot dan yang terkandung di dalamnya secara lebih mendalam. 2) Bagi mahasiswa Pendidikan Bahasa dan Sastra Indonesia, penelitian ini dapat digunakan mahasiswa untuk menambah ide/gagasan baru yang lebih kreatif dan inovatif terkait teks anekdot. 3) Bagi Guru, Penelitian ini dapat digunakan sebagai bahan ajar untuk pembelajaran di kelas dan ditunjukkan kepada siswa agar menjadi pengetahuan yang bermanfaat untuk 
Mutiara Indah Fitria, Kuntoro

Teks Anekdot dalam Web Guru Pendidikan

(Pola, Struktur, Pesan Moral, dan Relevansinya bagi Pembelajaran Bahasa Indonesia SMA Kelas X)

kehidupan sehari-hari, serta sebagai media pendidikan karakter dan moral.

\section{DAFTAR PUSTAKA}

Jakarta:Elek Media Komputindo.

Arief, M. Rudyanto. (2011). Pemrograman Web Dinamis Menggunakan PHP dan MYSQL. Yogyakarta:Andi.

Bekti, Humaira. (2015). Dreamweaver CSG,CSS, dan Jquery. Yogyakarta: Andi Offset.

Chaer, Abdul. (2011). Cekakak Cekikik Jakarta. Jakarta: Rineka Cipta.

Mahsun. (2013). Pembelajaran Teks dalam Kurikulum 2013. kemendikbud.go.id. Diunduh pada 10-05-2021.

Keraf, Gorys. (2007). Argumentasi dan Narasi. Jakarta: Gramedia Pustaka Utama.

Ratna, S.U, Prof. Dr. Nyoman Kutha. (2014). Peranan Karya Sastra, Seni, dan Budaya dalam Pendidikan Karakter. Yogyakarta: Pustaka Pelajar.

Rusdiana, dan Dr. Hj. Qiqi Yulianti. (2014). Pendidikan Nilai. Bandung: CV Pustaka Setia.

Wijana, I Dewa Putu. (1995). Pemanfaatan Teks Humor dalam Pengajaran Aspekaspek Kebahasaan, 11/1995. 